\title{
The Role of Sentinel Events in the Measurement of Work-Related Stress
}

\author{
Ruggero Andrisano-Ruggieri, Mario Capunzo, Pietro Crescenzo, Rosa Ambrosio, \\ Riccardo Savastano, Giovanni Boccia \\ Department of Human, Philosophical and Educational Science, University of Salerno, Salerno, Italy \\ Email: rruggieri@unisa.it
}

Received 17 January 2015; accepted 1 February 2015; published 5 February 2015

Copyright (C) 2015 by authors and Scientific Research Publishing Inc.

This work is licensed under the Creative Commons Attribution International License (CC BY). http://creativecommons.org/licenses/by/4.0/

(c) (i) Open Access

\begin{abstract}
Literature has shown that sentinel events may be considered as markers for measuring workrelated stress levels. This aspect has been recognized by the Italian legislation, which requires its recognition for the measurement of occupational stress. This study aims to understand the role of sentinel events in the measurement of work-related stress. Samples of 249 subjects were divided in two balanced and proportional categories (inside sentinel events and outside sentinel events). At the samples the Organizational and Psychosocial Risk Assessment (OPRA) questionnaire was administered. The tests T-student and ANOVA from the OPRA results didn't show any statistically significant differences between the subjects belonging to the sentinel events and those not belonging.
\end{abstract}

\section{Keywords}

Work-Related Stress, Sentinel Events, OPRA Questionnaire, Occupational Stress

\section{Introduction}

The increased competitiveness in the job market, has led organizations to urgently ask employees to: be proactive, have initiative, work with all the staff, take full responsibility for their own professional development, adhere to high levels of performance and to complete the assigned tasks in a short time (Schaufeli \& Bakker, 2008). These environmental pressures influence both every day behaviours as well as the affective-cognitive sphere, encouraging the development of stress conditions (Cox, Griffiths, \& Rial-Gonzalez, 2002; Xanthopoulou, Bakker, Demerouti, \& Schaufeli, 2007).

The academicals interest for organizational well-being could be found in the increasing scientific production, which gave birth to a large and widespread consensus on work-related stress being a major problem in the 
workplace (Damiani, Frederico, Pinnarelli, Sammarco, \& Ricciardi, 2006; Jackson \& Rothmann, 2005; Marinaccio et al., 2013). In fact, it has a significant effect on both the health of employees (Damiani et al., 2006; Deitinger et al., 2009; Nahar, Hossain, Rahman, \& Bairagi, 2013; Nieuwenhuijsen, Bruinvels, \& Frings-Dresen, 2010; Sakketou, Galanakis, Varvogli, Chrousos, \& Darviri, 2014; Thorsteinsson, Brown, \& Richards, 2014; Von Onciul, 1996; Xiang, Coleman, Johannsson, \& Bates, 2014) as well as the productivity and competitiveness of companies (Damiani et al., 2006; Kerr, McHugh, \& McCrory, 2009; Magnavita \& Garbarino, 2013; Van der Klink, Blonk, Schene, \& Van Dijk, 2001; Xiang et al., 2014). It therefore seems appropriate to make an accurate assessment of the levels of perceived mental and physical fatigue and therefore an adequate management of conflicts at work to ensure the well-being of the production processes.

The commonly accepted idea is that the protection of physical and mental health of workers is closely related to job satisfaction and that this can improve business productivity (Lee, An, \& Noh, 2012; Visser, Smets, Oort, \& De Haes, 2003). It appears that job satisfaction promotes positive affectivity in employees, thereby increasing their ease in the working environment (Lee et al., 2012). It is believed that job satisfaction is mainly linked to the characteristics of the work environment rather than the individual variables (Cotton \& Hart, 2003; Kohantorabi \& Abolmaali, 2014; Lee et al., 2012; Xanthopoulou et al., 2007).

The attention given to the work environment is reflected in the prominence given to phenomena such as absenteeism, overtime, interpersonal conflicts, complaints, letters of recall, and injury rates that are reported in the literature as “sentinel events”. These are indicators of possible development of work-related stress (Deitinger et al., 2009; Magnavita \& Garbarino, 2013; Marcatto, D’Errico, Di Blas, \& Ferrante, 2011; Patronella et al., 2011) which appears to be linked to both the content (e.g. load and pace of work, shifts and working hours) and the work context (e.g. lack of control, lack of decision-making autonomy and support) (Bosma, Peter, Siegrist, \& Marmot, 1998; Giorgi, Leon-Perez, Cupelli, Mucci, \& Archangels, 2014; Homer, James, \& Siegel, 1990; Johnson et al., 2005; Kerr et al., 2009; Mausner-Dorsch, \& Eaton, 2000; Urbanetto et al., 2013).

Based on the provisions of the Agreement on the European Stress in the Workplace (08/10/2004), the Legislative Decree No. 81/2008 and the subsequent circular of the Ministry of Labour and Social Policy of 18/11/2010 have made mandatory in Italy the assessment of work-related stress (Deitinger et al., 2009; Magnavita \& Garbarino, 2013; Marcatto et al., 2011; Patronella et al., 2011), proposing guidelines that leave operators free to use methodologies deemed most appropriate. This legislation recognizes the sentinel events a prominent role in the development of work-related stress to the point that asks operators to detect their presence and distribution in the preliminary measurement of work-related stress. In particular, the sentinel events are considered strategic elements in the construction of homogenous classes of psychosocial risk. These classes may represent risk indicators of stress, which are objective and verifiable (Bosma et al., 1998; Giorgi et al., 2014; Homer et al., 1990; Johnson et al., 2005; Kerr et al., 2009; Mausner-Dorsch \& Eaton, 2000; Urbanetto et al., 2013). Their presence in the workplace, however, is not in itself indicative of stress-related diseases (Faragher, Cooper, \& Cartwright, 2004) as to adversely affect the worker and his behaviour. There are both individual components (e.g. selfesteem, self-efficacy, coping strategies) (Antoniou, Ploumpi, \& Ntalla, 2013; Sakketou et al., 2014) as well as the organizational culture and climate (Neal, Griffin, \& Hart, 2000; Parker et al., 2003; Zhang \& Lee, 2010). However, the current regulations and the most reliable theories on work-related stress give to job characteristics (e.g., autonomy, variety of tasks, job application, social support, feedback, safety at work, gains) a prominent role, compared to the individual variables, in the possible developments of work-related stress. These factors seem to have a decisive influence on the worker perception of the work situation. As a result, they are fundamental aspects of the assessment of psychosocial risks (Deitinger et al., 2009).

This study aims to understand the role of the sentinel events in the measurement of work-related stress on the basis of the information provided by the constraints of the Italian legislation. The following is a presentation of preliminary data from a very complex study, which covered workers of a debt collection company present throughout the Italian territory, of which a significant amount of data is still being processed.

\section{Method}

\subsection{Sample}

It consists of a non-probabilistic balanced and reasonably chosen sample in relation to organizational variables related to the job content. It is made up of 249 subjects from a population of 770 people; thus, it represents about $30 \%$ of the population. Practically, it is made up of individuals who fall into the following risk categories: inside 
sentinel events (ISE) and outside sentinel events (OSE). Considering this partition, it was formed taking into account the work function — corporate (C group), governance (G group), back office (B group)—and organization conditions as well the length of service: Cluster 1 ( $<5$ years), Cluster 2 (5 - 15 years), Clusters 3 (16 - 25 years), Cluster 4 ( $>25$ years).

\subsection{Instrument}

An OPRA questionnaire (Organizational and Psychosocial Risk Assessment) was used to assess work-related stress (Magnani, Mancini, \& Majer, 2011). OPRA is a multifactorial questionnaire developed by Academy to evaluate effectively the presence of psychosocial risk factors as well as work-related stress conditions in accordance to the requirements of the Legislative Decree No. 81/08. The solid theoretical platform on which it was developed the instrument is supported by qualitative and quantitative empirical tests that confirm the psychometrics properties. It is structured in three parts, each of which evaluates different aspects of the work experience based on a 5-point Likert scale (from "never" to "always") through three indices:

$>$ Risk index $(R I)$. It consists of items that assess the malaise resulted from a condition of low identification with the group or organization to which they belong, by low job satisfaction, poor confidence in the organization and from the consideration of wanting to leave their place of work. This index has Cronbach's alpha .71 .

> Inventory of the sources of risk (ISR). It consists of items distributed over nine factors responsible for evaluating the sources of stress at work that may cause distress or discomfort. This index has Cronbach's alpha .67.

$>$ Mental and physical health (MPH). It is a two-dimensional scale (16 items) that assesses the presence and frequency of physical and psychological disturbances. It depicts an aggregated score that provides an estimation of the effects resulting from stressful working conditions. This index has Cronbach’s alpha .90.

\subsection{Procedure}

A sentinel events database (SED) made up of a double-entry table was created: in the line there are the ID codes of the subjects; while in the column there are the variables related to sentinel events (turnover, sick days, overtime, working unit shift, absences etc.). Thus, we were able to perform the intersections between structural variables-namely elements structuring work activities-(e.g., role, work function, etc.) and the sentinel events. Moreover, the sentinel events were monitored in relation to the parameters of average and duration. In this way, the homogeneous classes of risk were obtained. This survey highlights that $71.89 \%$ of the population was affected by the sentinel events, while the remaining $28.11 \%$ was left out. Thus, we proceeded to performing a sampling that takes into consideration the presence or absence of sentinel events according to the work function, by role, by working unit and territorial unit.

The results obtained after the administration of the OPRA questionnaire were then subjected to statistical analysis using the Software STATA 12.1 (STATA CORP.). The Shapiro Wilk test was used to ensure that the same data were in accordance with a normal distribution. Subsequently the T-student was conducted to operate a comparison between the means of subjects ISE and OSE in relation to the total score of the three indexes OPRA. Furthermore, the correlations between the different OPRA indexes were calculated in order to evaluate a possible relationship between the variables. Subsequent researches were operated by ANOVA in order to understand if there where any differences in the score of the three OPRA indexes in relation to the subjects ISE and OSE due to variables such as length of service and job function.

\section{Results}

The comparison between the means of subjects ISE and OSE by T-student does not show statistically significant differences in relation to the three indices OPRA, RI, ISR, and MPH with a $p$ value > .05 (Table 1). Therefore, the sentinel events do not evidence any difference in the results.

All the stratifications for the three indices (RI, ISR, and MPH) for work functions (B, C, G group) and for the length of service (Cluster 1, 2, 3, 4) were done. The comparison between the means of ISE and OSE is significant only RI in relation to job function $\mathrm{G}$ with $p$ value .003 and the length of service (5 - 15) at $p$ value .0174 (Table 2). Consequently, subjects ISE belonging to the functions $\mathrm{G}$ and seniority is 5 - 15 have different average 
Table 1. T-student between ISE e OSE for OPRA indexes.

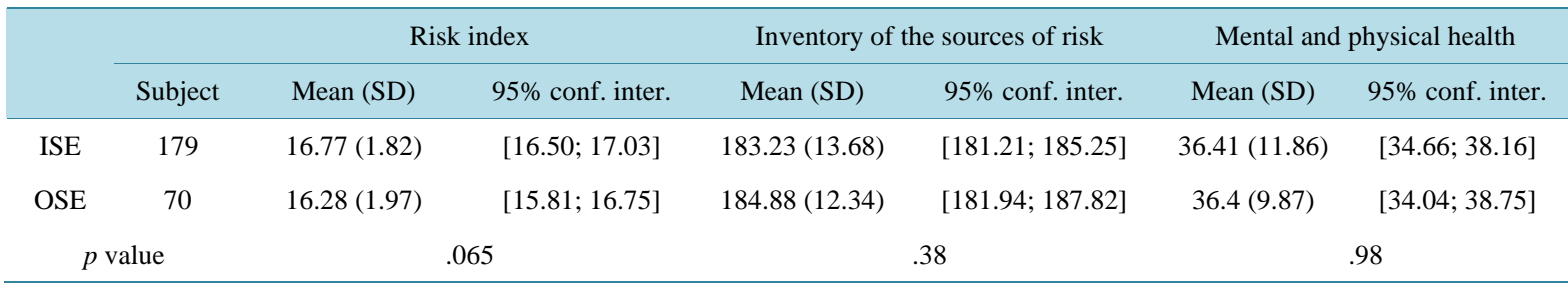

Note: T student with unpaired data with equal variance.

Table 2. T-student between ISE e OSE stratified for risk index.

\begin{tabular}{|c|c|c|c|c|c|c|c|}
\hline \multirow[b]{2}{*}{ RI } & \multirow[b]{2}{*}{ obs } & \multicolumn{2}{|r|}{ ISE } & \multicolumn{4}{|c|}{ OSE } \\
\hline & & Mean (SD) & $95 \%$ conf. interval & obs & Mean (SD) & $95 \%$ conf. interval & $p$ value \\
\hline Cluster 2 & 97 & 16.97 (1.99) & {$[16.57 ; 17.38]$} & 47 & $16.14(1.82)$ & {$[15.61 ; 16.68]$} & .017 \\
\hline G group & 59 & $17.01(1.61)$ & {$[16.59 ; 17.43]$} & 7 & $15(1.91)$ & {$[13.22 ; 16.77]$} & .003 \\
\hline
\end{tabular}

Note: T student with unpaired data with equal variance.

compared to the same belonging to OSE. There is no statistical significance in the stratification made for indexes ISR and MPH in relation to specified variables and related to the subjects ISE and OSE.

The calculation of the Coefficient of Spearman indicates the absence of a significant correlation between RI and the other two indexes ISR $\left(\mathrm{r}_{\mathrm{s}}=.04 ; p\right.$ value .52$)$ and MPH $\left(\mathrm{r}_{\mathrm{s}}=.07 ; p\right.$ value $\left.=.23\right)$. While ISR and MPH show a significant correlation even if in a medium low average $\left(\mathrm{r}_{\mathrm{s}}=.26 ; p\right.$ value $\left.=.00\right)$ (Table 3$)$.

The results of ANOVA performed to verify any significant difference in the means between the various company BCG, do not show a statistically significant difference between the means of these groups, respectively, RI, ISR and MPH with a $p$ value $>.05$ (Table 4).

The ANOVA for length of service does not show significant differences between the means of several groups (Table 5).

\section{Discussion}

The results show a substantial absence of difference between the scores reported by the subjects ISE and OSE in relation to the OPRA indexes. In our view, this can be explained by the time elapsed between the detection of the data relating to the identification of sentinel events, the subsequent construction of the SED, the definition of the sample and at last the administration of the OPRA questionnaire. These steps have required a whole year of work. This time frame is able to refine the different working conditions (e.g. workload, turnover, overtime, etc.) as these are by nature mutable because of the changes in market conditions (De Croon, Blonk, De Zwart, FringsDresen, \& Broersen, 2002). This time dimension is not unknown to the diagnostic criteria for disorders related to stress (Halpern, 2005; Leymann \& Gustafsson, 1996). The DSM-V with American Psychiatric Association (2013), reports that in fact both the continuous and persistent exposure to stressors promotes the development of certain diseases by stress rather than others. Moreover, the work of National Institute for Occupational Safety and Health (1999) has shown how this aspect of temporal continuity is able to have a negative impact on different levels of strain regardless of the personality variables (Fraccaroli \& Balducci, 2011).

Hence, the time factor seems to play a crucial role in relation to the value that the sentinel events can assume in the measurement of work-related stress. This element, in our view, also explains the absence of statistical significance compared to the stratification of the results for the work functions (B, C, G group) and the length of service (Clusters 1, 2, 3, 4) in relation to the indexes IRS and MPH. However, these variables become statically significant for RI producing a difference between the subjects ISE and OSE.

This fact, apparently in contradiction with the above statements, may find a possible explanation based on the absence of correlation between the RI and the remaining two indices IRS and MPH. This means that the RI moves independently in relation to the other two indexes. The RI consists of aspects that have to do with the identification with the working group and/or organization, job satisfaction and confidence in the company as the intention to leave the workplace. It is generally accepted that these factors-which refer to a sense of belonging 
Table 3. Correlation of spearman between risk index, inventory of the sources of risk, mental and physical health.

\begin{tabular}{ccccc}
\hline & ISR & MPH & MPH \\
\hline RI & $\rho=.04$ & $\rho=.07$ & ISR & $\rho=.26$ \\
$p$ value & .52 & .23 & $p$ value & .00 \\
\hline
\end{tabular}

Table 4. ANOVA for work functions (back office, corporate, governance).

\begin{tabular}{|c|c|c|c|c|}
\hline & & Risk index & Inventory of the sources of risk & Mental and physical health \\
\hline Work functions & Subject & Mean (SD) & Mean (SD) & Mean (SD) \\
\hline Group C & 123 & $16.55(1.87)$ & $183.76(13.94)$ & $36.06(11.04)$ \\
\hline Group B & 60 & $16.61(2)$ & $185.25(12.47)$ & $36.45(11.50)$ \\
\hline Group G & 66 & $16.80(1.74)$ & $182.16(12.89)$ & $37.03(11.81)$ \\
\hline \multicolumn{2}{|l|}{$\mathrm{F}$} & .38 & .84 & .16 \\
\hline \multicolumn{2}{|c|}{ Prob $>$ F } & .68 & .43 & .85 \\
\hline
\end{tabular}

Table 5. ANOVA for length of service ( $<5$ years; 5 - 15 years; 16 - 25 years; $>25$ years).

\begin{tabular}{|c|c|c|c|c|}
\hline & & Risk index & Inventory of the source of risk & Mental and physical health \\
\hline Length of service & Subject & Mean (SD) & Mean (SD) & Mean (SD) \\
\hline Cluster 1 & 85 & $16.68(1.74)$ & 181.51 (13.39) & $36.90(11.51)$ \\
\hline Cluster 2 & 144 & $16.70(1.97)$ & $184.60(13.18)$ & 36.29 (11.17) \\
\hline Cluster 3 & 7 & $15.57(1.90)$ & $183.28(17.37)$ & 32.57 (11.29) \\
\hline Cluster 4 & 13 & $16.07(1.32)$ & 188.15 (11.17) & $36.61(12.56)$ \\
\hline $\mathrm{F}$ & & 1.23 & 1.48 & .33 \\
\hline Prob $>$ F & & .29 & .22 & .8 \\
\hline
\end{tabular}

(Mael \& Ashforth, 1992; Pozzi, Marta, Marzana, Gozzoli, \& Andrisano-Ruggieri, 2014)—may be a protective factor in relation to the development of a disease from stress determining welfare conditions.

However, in our opinion, other factors such as organizational culture may play a decisive role in shaping this sense of belonging in a different way, attributing a different meaning to it (Ruggieri, Pozzi, \& Ripamonti, 2014). Compared to our data, for example, subjects $\mathrm{G}$ appear most at risk because their job role requires a process responsibility - they perform executive functions and governance-which also involves the activities of the other two roles, that is, a sense of responsibility tout court, not closely connected with the mere individual activity of each of them as with the entire business process.

Instead the significant difference reported for RI only by those of Cluster 2, in our opinion, is explained by the difficulties on the behalf of those entities to combine aspects of working life with those of private life. As is known the work-balance (Allen, Herst, Bruck, \& Sutton, 2000; Hammeret, Bauer, \& Grandey, 2003; Turk, Davas, Tanik, \& Montgomery, 2014) plays a crucial role in the prevention of work-related stress. It points out that the average age of workers examined is about 40 years, and most of them fall into this category of service length. The pressures to which they are subjected are as much of working nature as probably related to their new family as well as the original one. In particular, in Italy, the link with the family is as much a constraint as a resource to the condition of well-being (Naldini \& Saraceno, 2007; Peery-Jenkis, Repetti, \& Crouter, 2000).

\section{Conclusion}

The results show a substantial absence of difference between the scores reported by the subjects ISE and OSE. They confirm the literature data that work contents and conditions are critical elements in the measurement of work related stress. Concurrently, they point out the need to grasp their variations in order to a time dimension. The time prospective in the measurement of work-related stress can have a crucial role in relation to the value 
that the sentinel events can assume, but it can make a useful contribution for understanding the onset of mental and physical condition of malaise.

\section{Limitations and Future Research}

The study certainly has some limitations. Based on the results obtained, we believe that an appropriate assessment of the relationship between sentinel events and work-related stress is possible only through a longitudinal study. This would allow to properly assess the effects of continuous exposure to stressors in terms of duration and frequency (Gorrese \& Ruggieri, 2012, 2013). Other variables not to be overlooked are the personality characteristics (e.g., self-esteem, self-efficacy, coping strategies, sense of coherence) by reason of the fact that they are able to influence the perception and evaluation of stressors as well as provide a different answer in terms of coping strategies (Cotton \& Hart, 2003; Rothmann, Steyn, \& Mostert, 2005). Exceedingly, it would be necessary to cross these data with those related to organizational culture, in order to have an overall view of the onset of work-related stress. (Xanthopoulou et al., 2007).

Future research should therefore focus on the relationship between stressors and exposure time to these stressors, taking into account the active dynamics in the workplace.

\section{References}

Allen, T. D., Herst, D. E. L., Bruck, C. S., \& Sutton, M. (2000). Consequences Associated with Work-to-Family Conflict: A Review and Agenda for Future Research. Journal of Occupational Health Psychology, 5, 278-308. http://dx.doi.org/10.1037/1076-8998.5.2.278

American Psychiatric Association (2013). Diagnostic and Statistical Manual of Mental Disorders (5th ed.). Washington DC: American Psychiatric Publishing. http://dx.doi.org/10.1176/appi.books.9780890425596

Antoniou, A. S., Ploumpi, A., \& Ntalla, M. (2013). Occupational Stress and Professional Burnout in Teachers of Primary and Secondary Education: The Role of Coping Strategies. Psychology, 4, 349-355. http://dx.doi.org/10.4236/psych.2013.43A051

Bosma, H., Peter, R., Siegrist, R. J., \& Marmot, M. (1998). Two Alternative Job Stress Models and the Risk of Coronary Heart Disease. American Journal of Public Health, 88, 68-74. http://www.ncbi.nlm.nih.gov/pubmed/9584036 http://dx.doi.org/10.2105/AJPH.88.1.68

Cotton, P., \& Hart, P. M. (2003). Occupational Wellbeing and Performance: A Review of Organizational Health Research. Australian Psychologist, 38, 118-127. http://dx.doi.org/10.1080/00050060310001707117

Cox, T., Griffiths, A., \& Rial-Gonzalez, E. (2002). Work-Related Stress: The European Picture. Magazine of the European Agency for Safety and Health at Work, 5, 4-6. https://osha.europa.eu/en/publications/magazine/5

Damiani, G., Federico, B., Pinnarelli, L., Sammarco, A., \& Ricciardi, W. (2006). Evaluating the Effect of Stress Management Programmers at the Work-Site on Absenteeism Reduction: A Systematic Review. Italian Journal of Public Health, 3 , 38-43.

De Croon, E. M., Blonk, R. W. B., De Zwart, B. C. H., Frings-Dresen, M. H. W., \& Broersen, J. P. J. (2002). Job Stress, Fatigue, and Job Dissatisfaction in Dutch Lorry Drivers: Towards an Occupation Specific Model of Job Demands and Control. Occupational Environmental Medicine, 59, 356-361. http://dx.doi.org/10.1136/oem.59.6.356

Deitinger, P., Nardella, C., Bentivenga, R., Ghelli, M., Persechino, B., \& Iavicoli, S. D. (2009). Lgs. 81/2008: Conferme e novità in tema di stress correlato al lavoro. Giornale Italiano di Medicina del Lavoro ed Ergonomia, 31, $154-162$.

Faragher, E. B., Cooper, C. L., \& Cartwright, S. (2004). A Shortened Stress Evaluation Tool (ASSET). Stress and Health, 20, 189-201. http://dx.doi.org/10.1002/smi.1010

Fraccaroli, F., \& Balducci, C. (2011). Stress e rischi psicosociali nelle organizzazioni. Bologna: Il Mulino.

Giorgi, G., Leon-Perez, J. M., Cupelli, V., Mucci, N., \& Arcangeli, G. (2014). Do I Just Look Stressed or Am I Stressed? Work-Related Stress in a Sample of Italian Employees. Industrial Health, 52, 43-53.

http://dx.doi.org/10.2486/indhealth.2012-0164

Gorrese, A., \& Ruggieri, R. (2012). Peer Attachment: A Meta-Analytic Review of Gender and Age Differences and Associations with Parent Attachment. Journal of Youth and Adolescence, 41, 650-672. http://dx.doi.org/10.1007/s10964-012-9759-6

Gorrese, A., \& Ruggieri, R. (2013). Peer Attachment and Self-Esteem: A Meta-Analytic Review. Personality and Individual Differences, 55, 559-568. http://dx.doi.org/10.1016/j.paid.2013.04.025

Halpern, D. F. (2005). How Time-Flexible Work Policies Can Reduce Stress, Improve Health, and Save Money. Stress and Health, 21, 157-168. http://dx.doi.org/10.1002/smi.1049 
Hammeret, L. B., Bauer, T. N., \& Grandey, A. A. (2003). Work-Family Conflict and Work-Related Withdrawal Behaviors. Journal of Business and Psychology, 17, 419-436. http://dx.doi.org/10.1023/A:1022820609967

http://link.springer.com/article/10.1023\%2FA\%3A1022820609967

Homer, C. J., James, S. A., \& Siegel, E. (1990). Work-Related Psychosocial Stress and Risk of Preterm, Low Birth Weight, Delivery. American Journal of Public Health, 80, 173-177. http://dx.doi.org/10.2105/AJPH.80.2.173 http://www.ncbi.nlm.nih.gov/pubmed/2297061

Jackson, L., \& Rothmann, S. (2005). Work-Related Well-Being of Educators in a District of the North-West Province. Perspectives in Education, 23, 107-122. http://www.ianrothmann.com/pub/persed_v23_n3_a11.pdf

Johnson, S., Cooper, C., Cartwright, S., Donald, I., Taylor, P., \& Millet, C. (2005). The Experience of Work-Related Stress across Occupations. Journal of Managerial Psychology, 20, 178-187. http://dx.doi.org/10.1108/02683940510579803

Kerr, R., McHugh, M., \& McCrory, M. (2009). HSE Management Standards and Stress-Related Work Outcomes. Occupational Medicine, 59, 574-579. http://dx.doi.org/10.1093/occmed/kqp146

Kohantorabi, F., \& Abolmaali, K. (2014). The Prediction of Job Satisfaction Based on Coping Skills in Pilots and Assistant of Pilots. Journal of Service Science and Management, 7, 260-266. http://dx.doi.org/10.4236/jssm.2014.73023

Lee, C., An, M., \& Noh, Y. (2012). The Social Dimension of Service Worker's Job Satisfaction: The Perspective of Flight Attendants. Journal of Service Science and Management, 5, 160-170. http://dx.doi.org/10.4236/jssm.2012.52020

Leymann, H., \& Gustafsson, A. (1996). Mobbing at Work and the Development of Post-Traumatic Stress Disorders. European Journal of Work and Organizational Psychology, 5, 251-275. http://dx.doi.org/10.1080/13594329608414858

Mael, F., \& Ashforth, B. E. (1992). Alumni and Their Alma Mater: A Partial Test of the Reformulated Model of Organizational Identification. Journal of Organizational Behavior, 13, 103-123. http://dx.doi.org/10.1002/job.4030100202

Magnani, M., Mancini, G. A., \& Majer, V. (2011). Organizational and Psychosocial Risk Assessment (OPRA). Florence: Giunti O.S.

Magnavita, N., \& Garbarino, S. (2013). Is Absence Related to Work Stress? A Repeated Cross-Sectional Study on a Special Police Force. American Journal of Industrial Medicine, 56, 765-775. http://dx.doi.org/10.1002/ajim.22155

Marcatto, F., D’Errico, G., Di Blas, L., \& Ferrante, D. (2011). La valutazionedello stress lavorocorrelato: Adattamentoitalianodell' HSE management standards work-related stress indicator tool. Giornale Italiano di Medicina del Lavoro ed Ergonomia, 33, 403-408.

Marinaccio, A., Ferrante, P., Corfiati, M., Di Tecco, C., Rondinone, B. M., Bonafede, M., Roncetti, M., \& Iavicoli, S. (2013). The Relevance of Socio-Demographic and Occupational Variables for the Assessment of Work-Related Stress Risk. BMC Public Health, 13, 1-9. http://dx.doi.org/10.1186/1471-2458-13-1157

Mausner-Dorsch, H., \& Eaton, W. W. (2000). Psychosocial Work Environment and Depression: Epidemiologic Assessment of the Demand-Control Model. American Journal of Public Health, 90, 1765-1770.

http://www.ncbi.nlm.nih.gov/pmc/articles/PMC1446399/ http://dx.doi.org/10.2105/AJPH.90.11.1765

Nahar, L., Hossain, A., Rahman, A., \& Bairagi, A. (2013). The Relationship of Job Satisfaction, Job Stress, Mental Health of Government and Non-Government Employees of Bangladesh. Psychology, 4, 520-525.

Naldini, M., \& Saraceno, C. (2007). Conciliare famiglia e lavoro: Vecchi e nuovipattitrasessi e generazioni. Bologna: Il Mulino.

National Institute for Occupational Safety and Health (1999). Stress at Work. www.cdc.gov/niosh/docs/99-101/pdfs/99-101.pdf

Neal, A., Griffin, M. A., \& Hart, P. M. (2000). The Impact of Organizational Climate on Safety Climate and Individual Behavior. Safety Science, 34, 99-109.

Nieuwenhuijsen, K., Bruinvels, D., \& Frings-Dresen, M. (2010). Psychosocial Work Environment and Stress-Related Disorders, a Systematic Review. Occupational Medicine, 60, 277-286. http://dx.doi.org/10.1093/occmed/kqq081

Parker, C. P., Baltes, B. B., Young, S. A., Huff, J. W., Altmann, R. A., Lacost, H. A., \& Roberts, J. E. (2003). Relationships between Psychological Climate Perceptions and Work Outcomes: A Meta-Analytic Review. Journal of Organizational Behavior, 24, 389-416. http://dx.doi.org/10.1002/job.198

Patronella, G., Latocca, R., De Vito, G., D’Orso, M. I., Riva, M. A., \& Cesana, G. (2011). Eventi sentinella stress lavorocorrelati in ambito ospedaliero e loro monitoraggio nel decennio 2001-2011. Giornale Italiano di Medicina ed Ergonomia, 33, 326-329.

Peery-Jenkis, M., Repetti, L. M., \& Crouter, A. C. (2000). Work and Family in the 1990s. Journal of Marriage and the Family, 62, 981-998. http://repetti.bol.ucla.edu/perry-jenkins\%20repetti\%20crouter.pdf http://dx.doi.org/10.1111/j.1741-3737.2000.00981.x

Pozzi, M., Marta, E., Marzana, D., Gozzoli, C., \& Andrisano-Ruggieri, R. (2014). Effect of the Psychological Sense of 
Community on the Psychological Well-Being in Older Volunteers. Europe’s Journal of Psychology, 10, 598-612. http://dx.doi.org/10.5964/ejop.v10i4.773

Rothmann, S., Steyn, L. J., \& Mostert, K. (2005). Job Stress, Sense of Coherence and Work Wellness in an Electricity Supply Organization. South African Journal of Business Management, 36, 55-63. http://www.ianrothmann.com/pub/busman_v36_n1_a6.pdf

Ruggieri, R., Pozzi, M., \& Ripamonti, S. (2014). Italian Family Business Cultures Involved in the Generational Change. Europe's Journal of Psychology, 10, 79-102. http://dx.doi.org/10.5964/ejop.v10i1.625

Sakketou, A., Galanakis, M., Varvogli, L., Chrousos, G., \& Darviri, C. (2014). Validation of the Greek Version of the "Job Stress Measure”. Psychology, 5, 1527-1535. http://dx.doi.org/10.4236/psych.2014.513163

Thorsteinsson, E. I., Brown, R., \& Richards, C. (2014). The Relationship between Work-Stress, Psychological Stress and Staff Health and Work Outcomes in Office Workers. Psychology, 5, 1301-1311. http://dx.doi.org/10.4236/psych.2014.510141

Turk, M., Davas, A., Tanik, F. A., \& Montgomery, A. J. (2014). Organizational Stressors, Work-Family Interface and the Role of Gender in the Hospital: Experiences from Turkey. British Journal of Health Psychology, 19, 442-458. http://dx.doi.org/10.1111/bjhp.12041

Urbanetto De Souza, J., Magalhaes, M. C. C., Maciel, V. O., Sant’Anna, V. M., Gustavo da Silva, A., Poli de Figuereido, C. E., \& Bosi de Souza Magnago, T. S. (2013). Work-Related Stress According to the Demand-Control Model and Minor Psychic Disorders in Nursing Workers. Revista da Escola de Enfermagem da USP, 47, 1180-1186. http://dx.doi.org/10.1590/S0080-623420130000500024

Van der Klink, J. J. L., Blonk, R. W., Schene, A. H., \& Van Dijk, F. J. (2001). The Benefits of Interventions for WorkRelated Stress. American Journal of Public Health, 91, 270-276. http://dx.doi.org/10.2105/AJPH.91.2.270

Visser, M. R. M., Smets, E. A. M., Oort, F. J., \& De Haes, C. J. M. (2003). Stress, Satisfaction and Burnout among Dutch Medical Specialists. Canadian Medical Association Journal, 168, 271-276.

http://www.ncbi.nlm.nih.gov/pmc/articles/PMC140468/

Von Onciul, J. (1996). ABC of Work Related Disorders: Stress at Work. Bio-Medical Journal, 313, 745-748. http://dx.doi.org/10.1136/bmj.313.7059.745

Xanthopoulou, D., Bakker, A. B., Demerouti, E, \& Schaufeli, W. B. (2007). The Role of Personal Resources in the Job Demands-Resources Model. International Journal of Stress Management, 14, 121-141. http://dx.doi.org/10.1037/1072-5245.14.2.121

Xiang, H., Coleman, S., Johannsson, M., \& Bates, R. (2014). Work-Place Stress and Job Satisfaction among Biologics Development Professionals. Health, 6, 1790-1802. http://dx.doi.org/10.4236/health.2014.614211

Zhang, G., \& Lee, G. (2010) The Moderation Effects of Perceptions of Organizational Politics on the Relationship between Work Stress and Turnover Intention: An Empirical Study about Civilian in Skeleton Government of China. iBusiness, 2, 268-273. http://dx.doi.org/10.4236/ib.2010.23034 
Scientific Research Publishing (SCIRP) is one of the largest Open Access journal publishers. It is currently publishing more than 200 open access, online, peer-reviewed journals covering a wide range of academic disciplines. SCIRP serves the worldwide academic communities and contributes to the progress and application of science with its publication.

Other selected journals from SCIRP are listed as below. Submit your manuscript to us via either submit@scirp.org or Online Submission Portal.
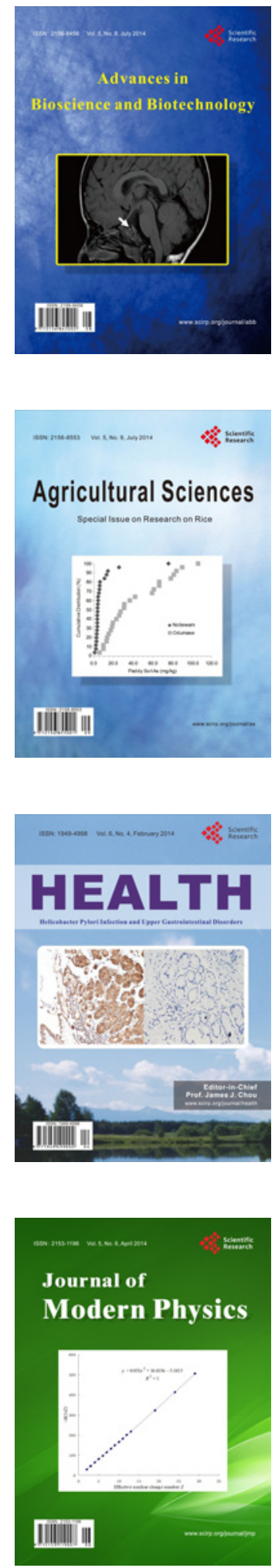
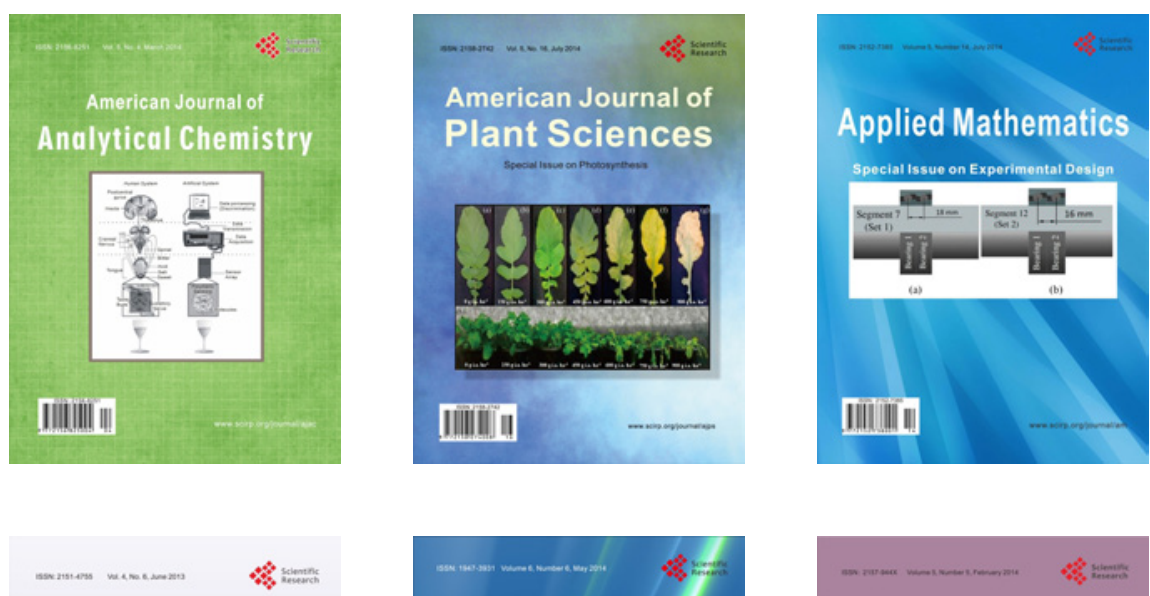

Creative Education
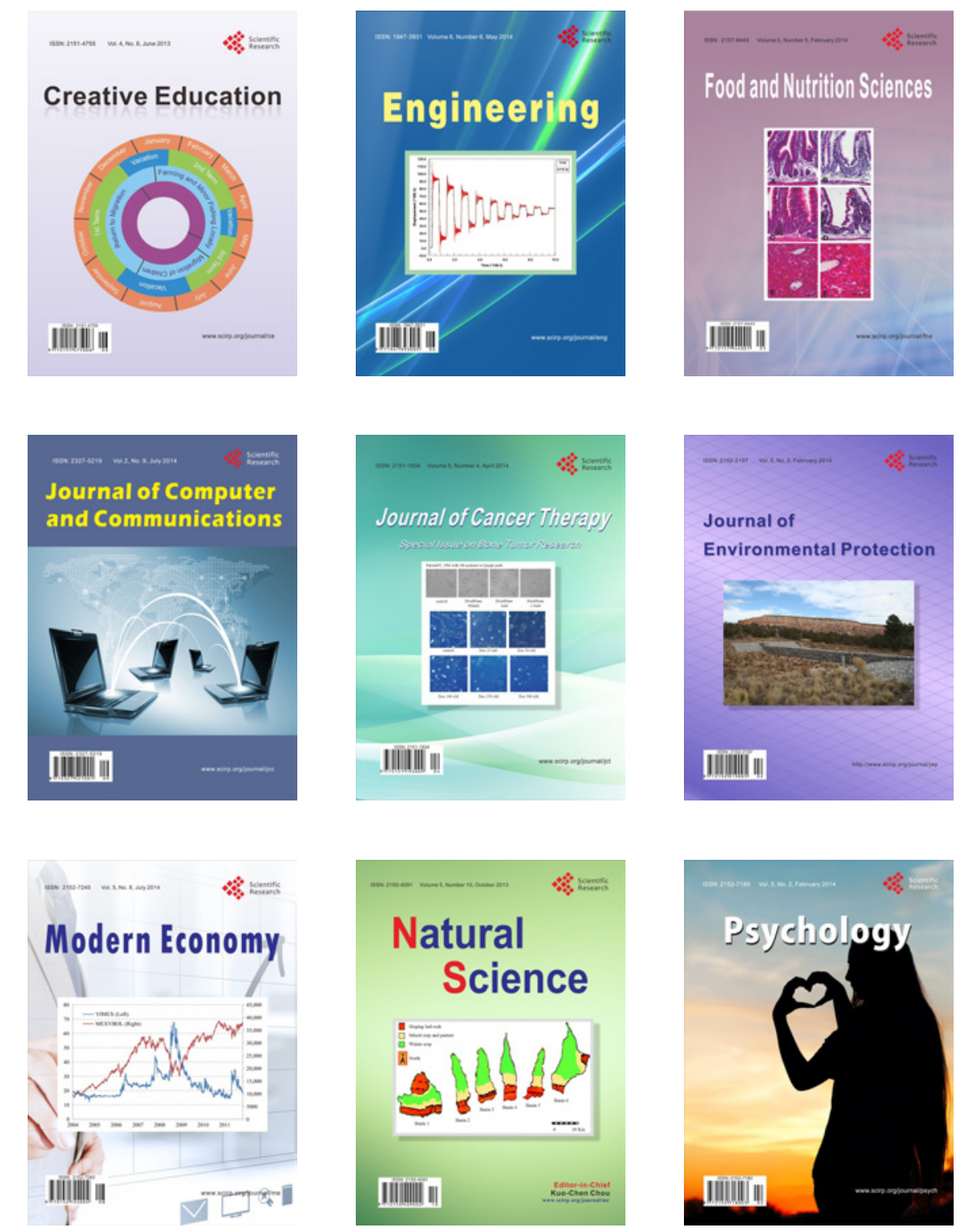